\title{
Prevalence of burnout and its correlates among female primary school teachers in the southern province of Sri Lanka
}

\author{
PV De Silva, CG Hewage, P. Fonseka \\ Faculty of Medicine, University of Ruhuna, Galle, Sri Lanka
}

Email address:

pvijithadesilva123@yahoo.com (PV De Silva)

\section{To cite this article:}

PV De Silva, CG Hewage, P. Fonseka. Prevalence of Burnout and Its Correlates among Female Primary School Teachers in the Southern Province of Sri Lanka. European Journal of Preventive Medicine. Special Issue: New Frontiers of Public Health from the Pearl of Indian Ocean, Sri Lanka. Vol. 3, No. 2-1, 2015, pp. 9-14. doi: 10.11648/j.ejpm.s.2015030201.13

\begin{abstract}
Introduction: Teaching is considered as one of the most important profession in the world today. In the past it was considered as a rather routine job without hard or hazardous work. However the present day school teachers have to play multiple roles in their day-to-day work with children, colleagues and administrators. Therefore teaching is now considered as a high stress profession. As a result there was a growing concern among researchers about teachers' mental health during last few decades. Several researchers have identified number of mental health problems of teachers including burnout. Burnout has not studied among teachers in Sri Lanka. Objective: The present study was planned to determine the prevalence and risk factors of burnout among female primary school teachers in the Southern Province of Sri Lanka. Methodology: Out of the female primary school teachers employed in the southern province of Sri Lanka, 660 teachers were selected using multi stage cluster sampling method. A self-administered questionnaire was used for the data collection. It consists with three broad sections: Socio-demographic characteristics, Occupational and life style factors and validated Sinhala version of Maslach Burnout Inventory- Educators Survey (MBI-ES-Sin). For identification of correlates of burnout, all the teachers identified as having burnout were selected as cases and double the number of cases was randomly selected from the teachers who were identified as not having burnout as controls. Results: Overall prevalence of burnout among female primary school teachers in the Southern Province was 115.6 per 1000 population. The prevalence rate for burnout was highest (157.8/1000 population) in the Hambanthota district. A stepwise increase in prevalence of burnout was observed from Galle (96/1000 population), Matara (105/1000 population) to Hambanthota district. Following the logistic regression analysis female primary school teachers more than 20 years in teaching profession, female primary school teachers who travel more than 10 kilometers daily to school, teachers doing home work more than 5 hours per week, teachers who participating in school activities during weekend, teachers who sleep less than 7 hours per day and teachers who are having one hour or less leisure time per day were identified as having significantly higher level of burnout. Conclusions: Burnout is a problem among female primary school teachers in Sri Lanka. Therefore, it is recommended that relevant authorities take necessary steps to address the factors contributing to the teacher burnout.
\end{abstract}

Keywords: Teachers' Health, Mental Health, Burnout

\section{Introduction}

The teacher, more often than not a woman, is the essential feature of any primary school classroom in Sri Lanka. She stays in the classroom for six hours a day, five days per week, with children varying in numbers from 20 to 50 . The primary class teacher usually works alone and is totally responsible for the physical, emotional, social and intellectual development of the children in her class.

Primary school teachers have to play multiple roles in their day-to-day work with children, colleagues and administrators. They are called upon to be in loco parentis, social worker, counsellor, mediator, first aid officer, fundraiser, disciplinarian and sports coordinator [1]. However, for most of these roles the teacher is not properly trained or prepared.

In addition to playing multiple roles in the school, many women teachers work the second shift at home. There, she 
has to play multiple roles of wife, mother, sister and daughter or daughter in law. Since women teachers work this unpaid 'second shift' at home, they are not in a position to rest [1]. A primary teacher's work connected with teaching is not limited to the six hours at school. There is always some preparation and homework pertaining to her teaching to be attended to before the next morning.

Teaching is now considered a highly stressful profession. Stressful events such as unruly students, impersonal administration, poorly organized timetables, poor working conditions, multiple role demands, increased workloads, the pressure and pace of curriculum changes, negative public attitudes, job dissatisfaction, low salary, lack of promotional opportunities, poor accommodation, lack of teaching materials contribute to teachers' stress [2].

Occupational stress occurs more frequently in peoples' lives than the stress of separation and loss. It, therefore, probably accounts for more total stress than almost any other source. Burnout is a prolonged response to chronic emotional and interpersonal stressors on the job [3]. Burnout is a syndrome characterized by extreme physical and mental fatigue and emotional exhaustion. Several researchers have defined burnout differently. However, the most commonly accepted definition comes from Maslach (1981) who defines burnout as emotional exhaustion, depersonalization and reduced personal accomplishment that can occur among individuals who do "People Work of some kind" [4].

Emotional exhaustion is the core component of burnout, which is characterized by fatigue and weariness that develop as emotional energies are drained. When these feelings become chronic, teachers find they can no longer give of themselves to students as they once could [5]. As a result, teachers begin to experience negative feelings and display negative attitudes towards their students. Maslach describes this state as depersonalization. The final component of teacher burnout is considered as a feeling of low personal accomplishment in their job [4]. This may also have a critical impact on teacher's satisfaction. Therefore, teacher stress/burnout is a major issue that is likely to have serious negative effects on the quality of education and on the lives of children [6].

A study conducted in the United Kingdom found that teachers, nurses, managers and professionals were at high risk of burnout. In all these groups, at least $20 \%$ reported burnout. Among teachers burnout was found to be $40 \%$ [7]. Several studies have found gender, age, marital status, workload, academic rank, changing education policies, type of school, the class they teach and years of teaching as predictors of burnout [8]. Other variables associated with teacher burnout are isolation, dissatisfaction with pay and lack of administrative support [9]. A study done in Taiwanese primary schools found that $26 \%$ of primary teachers had burnout. The main cause of burnout was identified as changing education policies by Taiwanese government. Teachers who had a healthy home life reported less burnout. Teachers based in large schools did report a higher level of burnout. Most teachers had suggested reduction of the teachers' workload to prevent teachers' burnout [10]. In a study done in Alabama using the MBI, concluded that burnout varies with the type of school and with the class they teach [11]. Therefore, it is important to establish norms across the school settings to determine high-risk groups who deserve interventions. About one-third of Australian teachers and $5 \%$ to $20 \%$ of American teachers were found to have burnout [12]. Most studies of burnout have focused largely on the investigation of background variables like marital status, age, years of teaching and gender as predictors of burnout [8].

A study done in Auckland, New Zealand confirmed the validity of MBI for diagnosis of burnout. These teachers recorded significantly higher scores for MBI emotional exhaustion subscale. Increased drive for measurable goal achievement imposed on teachers by the school administration, lack of trust in teachers' professional adequacy, circumscribing school culture, disagreeable physical environments to work and increased workload were significant contributors for burnout [13]. Several researchers studied the teacher burnout in different world settings in comparison with the general population. According to all these studies, teachers showed significantly high burnout rates. Student misbehavior, poor working conditions, time pressure, low level of supervision and lack of support from colleagues were identified as contributors to the burnout [1416]. Some researchers found that teachers who are younger, unmarried and working in urban areas have higher levels of burnout [17-18]. According to a study conducted among teachers in Turkey, burnout was not associated with gender, marital status, and habits of drinking or smoking [12].

Education is considered the biggest investment of a nation. There have been many reforms implemented and proposed for upgrading primary education in Sri Lanka. The primary school teacher is the basis of primary schooling. However stress and burnout of teachers may have a direct impact on the quality of education since it can lead to sickness absence and attrition. However, new reforms in education in Sri Lanka have failed to recognize the issues pertaining to teachers' health. Occupational or public health personnel too have failed to recognize teaching of primary school children as a hazardous profession. Furthermore, occupational stress and burnout of teaching professionals have not been systematically researched despite the attention given to educational research in recent years in Sri Lanka.

Therefore, this study was aimed to identify the prevalence of burnout and its life style and occupational correlates among female primary school teachers in the Southern province of Sri Lanka. Provision of such information will facilitate policy makers to take necessary steps for the improvement of health among primary school teachers thus improving the quality of life of these teachers and the quality of education

\section{Methodology}

Southern province is one of the nine provinces in Sri 
Lanka. It consists of three districts, namely Galle, Matara and Hambantota. Southern province has a land area of 5383 square kilometers and the total population is 2464732 . There are 1131 state schools (442 in the Galle district, 374 in the Matara District and 315 in the Hambantota District) in the Southern Province. Schools have classified in to four categories according to the classes in those schools. They are $1 \mathrm{Ab}$ schools (schools with advanced level science stream classes), 1C schools (schools with only advanced level arts stream classes), Type 2 schools (schools with classes only up to ordinary level) and Type 3 schools (schools with classes only up to ordinary level). In the Southern Province There are $901 \mathrm{AB}$ schools, $2551 \mathrm{C}$ schools, 576 Type 2 schools and 210 Type 3 schools. There are 7461 female primary school teachers employed by the state educational authorities of the Southern Province.

Out of the above population, 660 teachers were selected using multi stage cluster sampling method. The size of the cluster was fixed to 20 teachers. Therefore 33 clusters were divided between three districts proportionate to the total female primary school teachers in each district. According to the female primary teacher population in each category of schools in each district, the total number of clusters allocated to a district was divided among different categories of schools

A self-administered questionnaire was used for the data collection. It consists with three broad sections: Sociodemographic characteristics, Occupational and life style factors and validated MBI-ES-Sin [19]. Data was collected only from the Sinhala-medium female primary school class teachers, who have worked in state schools of the Southern Province, for a continuous period of more than six months. Principal investigator collected all the data to ensure the completeness and the quality of data. For identification of correlates of burnout, all the teachers identified as having burnout were selected as cases and double the number of cases was randomly selected from the teachers who were identified as not having burnout as controls. Ethical clearance was obtained from the ethical review committee, Faculty of Medicine, University of Ruhuna and permission to collect data was obtained from the Provincial Director of Education in southern province. Permission was obtained by paying copy right fees from the original authors of MBI-ES to use in this study. Informed written consent was obtained from all the subjects prior to data collection. SPSS was used for the data analysis.

Table 1. Socio demographic and occupational factors of teachers

\begin{tabular}{|c|c|c|c|}
\hline \multicolumn{2}{|c|}{ Socio-demographic and occupational factors } & \multirow{2}{*}{$\begin{array}{l}\text { Number }(\mathbf{N}=\mathbf{6 4 0}) \\
362\end{array}$} & \multirow{2}{*}{$\begin{array}{l}\text { Percentage(\%) } \\
56.6\end{array}$} \\
\hline ( & Below 45 years & & \\
\hline Age & 45 years and above & 278 & 43.4 \\
\hline \multirow{4}{*}{ Marital status } & Single & 88 & 13.8 \\
\hline & Married & 536 & 83.8 \\
\hline & Widowed & 13 & 2.0 \\
\hline & Divorced & 3 & 0.5 \\
\hline \multirow{2}{*}{ Monthly Family income } & Up to SLR 35000 per month & 301 & 47.0 \\
\hline & Above SLR 35000 per month & 339 & 53.0 \\
\hline \multirow{2}{*}{ Educational status } & GCE A/L or below & 436 & 68.1 \\
\hline & Above GCE A/L & 204 & 31.9 \\
\hline \multirow{3}{*}{ District of school } & Galle & 250 & 39.1 \\
\hline & Matara & 219 & 34.2 \\
\hline & Hambanthota & 171 & 26.7 \\
\hline \multirow{4}{*}{ Category of School } & $1 \mathrm{AB}$ & 135 & 21.1 \\
\hline & $1 \mathrm{C}$ & 136 & 21.3 \\
\hline & Type 2 & 230 & 35.9 \\
\hline & Type 3 & 139 & 21.7 \\
\hline \multirow{2}{*}{ *Number of students in the class } & 30 or less & 380 & 60.0 \\
\hline & above 30 & 253 & 40.0 \\
\hline *Participation of & Yes & 252 & 39.8 \\
\hline extracurricular activities & No & 381 & 60.2 \\
\hline \multirow{2}{*}{ *Doing Private tuition } & Yes & 119 & 18.8 \\
\hline & No & 514 & 81.2 \\
\hline **Number of hours of & $<10$ & 58 & 48.7 \\
\hline Tuition per week & $\geq 10$ & 61 & 51.3 \\
\hline
\end{tabular}

$*_{\mathrm{n}}=633 * *_{\mathrm{n}}=119$

\section{Results}

Out of the 660 teachers selected, 640 (96.9\%) female primary school class teachers were completed the survey giving rise to a non response rate of $3.1 \%$. Selected sociodemographic and occupational factors were described in the Table1. Out of the 640 teachers, 74 were identified as having burnout. Therefore, overall prevalence of burnout among female primary school teachers in the Southern Province was 115.6 per 1000 population. Burnout prevalence was highest (148.1 per 1000 population) in female primary school teachers of $1 \mathrm{AB}$ schools while the lowest burnout prevalence was (95.6/1000 population) among female primary school teachers in category 2 schools. The prevalence rate for burnout was highest $(157.8 / 1000$ population $)$ in the 
Hambanthota district. A stepwise increase in prevalence of burnout was observed from Galle (96/1000 population), Matara (105/1000 population) to Hambanthota district.

Socio-demographic, life style and occupational factors of 74 teachers with burnout were compared with the 148 randomly selected teachers without burnout. In the Bivariate analysis large number of socio-demographic, life style and occupational factors such as age, marital status, social class, monthly salary, monthly family income, category of school, free periods per week, doing private tuition were not significantly different between teachers with and without burnout. A logistic regression analysis was carried out using all socio demographic, occupational and life style risk factors, which were identified as significantly associated with burnout in the bivariate analysis. All the variables were entered into the logistics model as dichotomous variables (Table 2).

According to the logistic regression analysis female primary school teachers more than 20 years in teaching profession, female primary school teachers who travel more than 10 kilometers daily to school, teachers doing home work more than 5 hours per week, teachers who participating in school activities during weekend, teachers who sleep less than 7 hours per day and teachers who are having one hour or less leisure time per day are having significantly higher level of burnout (Table 1).

Table 2. Logistic regression analysis of occupational and life style risk factors for burnout.

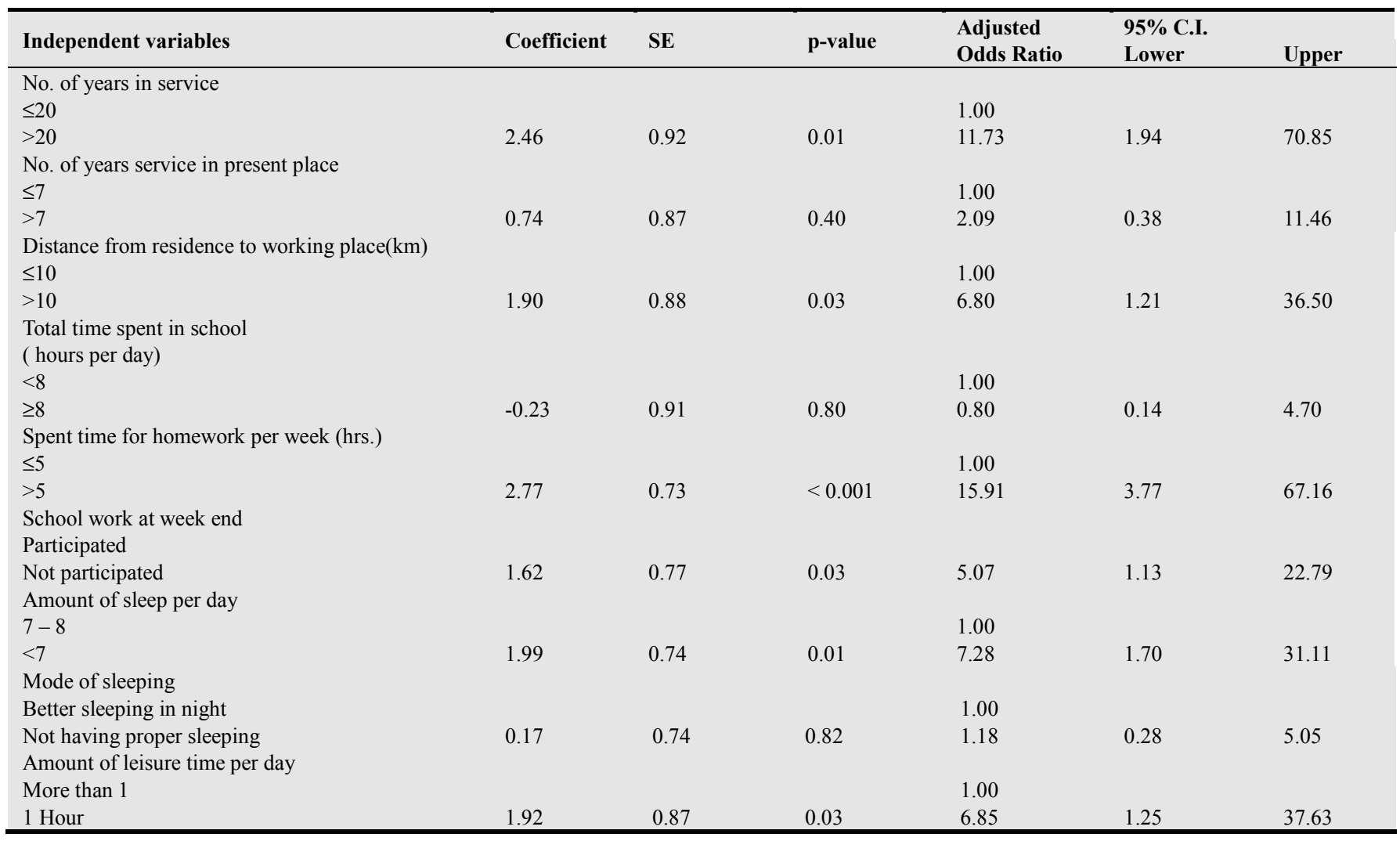

\section{Discussion}

Teaching is considered as one of the largest and most visible profession in the world today. In the past it was considered as a rather routine job and rarely seen as hard or hazardous work. However during the last few decades there was a growing concern among researchers about teachers' mental health and other health problems related to their profession. Several researchers have identified mental health problems of teachers and these problems varied from stress experienced by the teacher to final outcome of burnout [1416].

In the present study MBI-ES was considered to identify the burnout among the teachers due to several reasons. This was specifically developed to measure the burnout among the professionals in education service and commonly used to measure burnout throughout the world in different occupational settings. It was found to have good psychometric properties. Since this is a self-administered questionnaire which can be used in a large population within a short period of time. Considering the low English language proficiency among the selected study population, validated Sinhala translation of MBI-ES (MBI-ES-Sin) was used in this study [19].

The overall prevalence of burnout among female primary school teachers in the Southern Province was identified as 115.63 per 1000 population $(11.6 \%)$. No studies were identified from Sri Lanka or South Asian region on prevalence of burnout among teachers. The most of the studies on burnout have been conducted in developed countries, mainly in the western world. The only exception was a study conducted among Taiwanese primary school 
teachers. They found that $26 \%$ of primary teachers had burnout [10]. About one-third of Australian teachers were found to have burnout [8]. A study done in the United Kingdom found that $40 \%$ of teachers had burnout [7]. All these prevalence rates were much higher than the rates found in the present study. These differences may be attributed to the differences in socio-cultural backgrounds and occupational settings, which were found to have a direct impact on burnout. Out of the three districts in the Southern Province, the prevalence rate for burnout was highest $(15.8 \%)$ in the Hambanthota district. The schools in the Hambantota District are considered as uncongenial stations. Most of the teachers working in these areas are from faraway places. They are appointed to these uncongenial areas initially for three years. However, some of these teachers are not transferred to their hometowns even after serving six or seven years due to lack of replacements. These factors may have attributed to the high burnout prevalence among the teachers in Hambantota district.

In the next phase of the present study, case control approach was used to identify the socio-demographic, life style and occupational risk factors of burnout. This approach was selected considering its efficiency in time and cost, its suitability for rare diseases and diseases with long latency periods ant its ability to identification of multiple risk factors of burnout. Since burnout was found to have multi-factorial etiology by different researchers in different occupational settings including socio-demographic, occupational and life style factors, the present study was conducted as an unmatched case control study. All the teachers who were found to have burnout in the prevalence study were selected as cases. A simple random sample of teachers who were identified as not having burnout in the prevalence study was selected as controls. Selecting controls using the simple random sampling minimized selection bias in the case control study. To increase the power of the study included two controls per case.

All the socio-demographic, live style and occupational factors were compared using the bivariate analysis to identify the risk factors of burnout. Several previous studies found that teachers who are younger have higher levels of burnout [17-18]. But in the present study failed to identify age of teachers as a risk factor for burnout. Therefore, findings of the present study are inconsistent with the findings previous studies [17-18]. Both these previous studies, researchers calculated the mean burnout scores of different groups of teachers and compared them. However, in the present study teachers with and without burnout were identified and their factors were compared. This difference of methodology may have created the difference in the findings. Different researchers have found different associations between marital status and burnout. Some researchers found that teachers who are unmarried have higher levels of burnout [17-18]. However according to the study conducted in Turkey, marital status had no effect on burnout among Turkish teachers [12]. Similarly in the present study, there was no association between marital status and burnout among female primary school teachers. In the present study, monthly salary, monthly income or social class were not found to have association with the burnout status of the teachers. Even though there were differences in the income and social class, all teachers in Sri Lanka are receiving a satisfactory salary according to the Sri Lankan standards. This homogeneity of the subjects may be responsible for the above findings. However, some have identified low income as a risk factor for teacher burnout [12].

There are four categories of state sector schools in Sri Lanka. However the category of the school was not associated with an increased risk of burnout according to the bivariate analysis in the present study. Group of researchers too found that school size had no association with burnout of agriculture teachers in Ohio [20].

All the factors which were identified as significantly associated with burnout in the bivariate analysis were subjected to the logistic regression analysis to remove the effects of confounding. According to these analysis female primary school teachers more than 20 years in teaching profession were having significantly higher level of burnout compared to the teachers serving less than 20 years. Regarding the teaching experience, Demirel et al who studied burnout among Turkish teachers found that, no difference of burnout existed with the teaching experience [12]. This finding is inconsistent with the findings of the present study. There may be several factors for this inconsistency. The main difference was the difference in methodology where Demirel et al distributed the MBI-ES among teachers in the city Centrum of Sivas, Turkey, without knowing the burnout status of the teachers and later analysed the burnout scores of different groups of teachers using a student $t$ test. The non-response rate of this study was about $15 \%$ and another $8 \%$ were excluded from the analysis due to the incompleteness. Other than the above methodological issues, socio-cultural factors and occupational factors may be different to the Sri Lankan setting. These factors may have contributed to difference of finding regarding the teacher experience and burnout.

Female primary school teachers who travel more than 10 kilometers daily to school had significantly higher level of burnout compared to the teachers travelling less than 10 kilometers per day. According to available literature, this type of variable has not been studied. Most of the teachers who were more than 10 kilometres away may have used public transport to travel to their work place. The unsatisfactory status and the cost of public transport may have created an additional burden to the teacher which may have contributed to burnout. Teachers doing home work more than 5 hours per week and teachers who participating in school activities during weekends had high level of burnout compared to other teachers. These two factors represent the increased workload of teachers and is a well-documented source of burnout among teachers. Previous studies also found an increased risk of burnout with the increasing workload [10]. Teachers who sleep less than 7 hours per day and teachers who are having one hour or less leisure time per day were identified as 
having significantly higher level of burnout. However both these factors, less sleep and less leisure time per day are suggestive of lack of rest. Vance et al who studied stress among teachers identified that inability to find time to rest as an important source of stress [21].

In the present study, only the teachers who are currently working in schools were included. Teachers with severe burnout may have left the profession and therefore not included in the study. This bias can resulted in a lower estimate of the prevalence of burnout. We were unable to establish the temporal relationship of the factors identified due to the case control approach used in the present study.

However Burnout appears to be a problem of female primary school teachers. Therefore, periodic medical examinations may be useful to identify these problems to facilitate early interventions. With the introduction of the new mental health programme at district levels in Sri Lanka, educational and counseling programmes should be carried out in the schools. It is recommended to establish appropriate referral centers with adequate resources to prevent such problems. The present study found many risk factors for burnout among female primary school teachers. Some of these risk factors such as living more than ten kilometers away from school and participation of school activities at weekends can be prevented or minimized. Therefore, it is recommended that relevant authorities take necessary steps to address them.

\section{References}

[1] Kane P. Women's health: from womb to tomb. London: Macmillian press 1991.

[2] Jevne R, Zingle H. Living with broken dreams, A study of teachers health in Alberta: Alberta school employee benefit plan 1991.

[3] Maslach C, Jackson S, Leiter M. Maslach Burnout Inventory Manual. 3 rd edition, California, Consulting Psychologist Press 1996.

[4] Maslach C. Measurement of experience burnout. Journal of Occupational Behavior, 1981:2, 99-113.

[5] Schwab RL, Iwanicki EF. Who are burned out teachers? Educational Research Quarterly, 1982:7(2),5-16.

[6] Holt R, Fine MJ, Tollefson N. Mediating stress: Survival of the hardy. Psychology in the Schools, 1987:24, 51-58.
[7] Smith A. The scale of occupational stress. Cardiff University 2000, Available from www.untrammelled.co.uk.

[8] Byrne JJ. Teacher as hunger artist, burnout: It's causes effects and remedies. Contemporary Education,2003:69(2),86-91.

[9] Fimian MJ. Note on reliability of the Teacher Stress Inventory. Psychological Reports,1986: 59, 275-278.

[10] Kyriacou C, Chien P. Teachers stress in Taiwanese primary schools. Journal of Educational Enquiry,2004:5,2-5.

[11] Nagy S, Nagy MC. 1992. Longitudinal examination of teachers' burnout in a school district. Psychological Report, 71(2):523-31.

[12] Demirel Y, Guler N, Thoktamis A, Ozdemir D, Sezar RE. Burnout among high school teachers in Turkey. Middle east journal of family medicine. 2005:3,3.

[13] Anna W, Ken R, Michael O. Burnout among New Zealand primary school teachers. New Zealand journal of Psychology,2000:8,6-11.

[14] Russell DW, Altimaier E, Vanvelzen D. Job related stress, social support and burnout among classroom teachers. Journal Applied Psychology,1987: 72,269-74.

[15] Beer J. Burnout and stress, depression and self esteem of teachers. Psychology Report, 1992: 71,1331-6.

[16] Boyle GJ, Borg MG, Falzon JM, Baglioni AJ. Structural model of teacher stress. British Journal of Education Psychology, 1995:65,49-67.

[17] Anderson MB, Iwanicki EF. Teacher motivation and its relationship to burnout. Educational Administration Quaterly,1984:20,109-132.

[18] Gold Y. The relationship of six personal and life history variables to standing on three dimensions of the Maslach burnout Inventory in a sample of elementary and junior high school teachers. Educational and Psychological Measurement, 1985:45,377-387.

[19] De Silva PV, Hewage CG, Fonseka P. Measurement of burnout: Validation of the Sinhala translation of Maslach Burnout Inventory- Educators Survey among female primary school teachers in Sri Lanka. Galle Medical Journal 2013: 18(1):8-11.

[20] Chenevey JL, Ewing JC, Whittington MS. Teacher burnout in agriculture education. Journal of Agriculture Education, 2008:49(3): 12-22.

[21] Vance B, Miller S, Humphreys S, Reynolds F. Source and manifestation of occupational stress as reported by full time teachers working in a BIA school. Journal of American Indian Education, 1989:28(1-12). 